\title{
Knowledge, Attitude and Practice Concerning Human Papilloma Virus Infection and its Health Effects among Rural Women, Karnataka, South India
}

\author{
Sasidharanpillai Sabeena ${ }^{1 *}$, Parvati V Bhat ${ }^{2}$, Veena Kamath ${ }^{3}$, Sushama \\ Aswathyraj $^{1}$, Govindakarnavar Arunkumar ${ }^{1}$
}

\begin{abstract}
Background: Cervical cancer is one of the commonest cancers among women all over the world. The association of cervical cancer with human papilloma virus (HPV) is well established. Knowledge about the causal relationship between HPV and cervical cancer is important to make appropriate, evidence-based health care choices. In this context we conducted a community based study among women about the knowledge, attitude and practice about HPV infections and their health effects. Materials and Methods: A cross sectional interview based house to house survey was conducted with a validated data collection tool covering sociodemographic factors, knowledge, attitude and practice about HPV and its health effects, among 1020 women from a rural village, Perdoor, in Udupi district, Karnataka, India in 2013-14. Results: The mean age of participants was 38.9 years (SD=12.6). Study participants showed a high literacy rate $(85.7 \%)$. Only $2.4 \%$ of sexually exposed women had undergone Pap smear testing. Partners of $4.4 \%$ women had undergone circumcision and they belonged to the Muslim community. Male condom usage was reported by 26 women (2.6\%). However, none of the participants had heard of HPV and its health effects. Conclusions: This community based study found complete ignorance about HPV among rural South Indian women in spite of a high literacy level.
\end{abstract}

Keywords: Community study - human papilloma virus - knowledge - practice - India

Asian Pac J Cancer Prev, 16 (12), 5053-5058

\section{Introduction}

Cervical cancer is the fourth most common cancer among women worldwide after breast, colorectal and lung cancer(IARC, 2013 ). In India cervical cancer is the second commonest cancer among women between 15-44years of age (ICO, 2014). Age standardized annual incidence of cervical cancer in India is 22.0 per $1,00,000$. Globally $27 \%$ of total cervical cancer cases are from India which is home to $16-17 \%$ of world's women population (Shukla et al., 2009).

Cervical cancer develops through preneoplastic lesions with cellular dysplasia graded as 1,2, and 3. Hepatocellular cancers and cervical cancer represent two cancers which are mainly caused by viruses and against which vaccines have been developed. The link between cervical cancer and Human Papilloma virus (HPV) was first established in early 1980s by Harald zur Hausen. Recent molecular studies from India show high HPV prevalence of $94.6 \%$ in invasive cervical cancer (Bhatla et al., 2008). Mostly genital HPV infections are asymptomatic and the commonest outcome is resolution. There are more than 100 types of HPV and the types causing cancers are classified as High Risk HPV (HR-HPV). High risk HPV persisting for years can lead to development cervical intraepithelial neoplasia and cervical cancer.

Adoption of healthy life styles, genital hygiene and even acceptability of immunization depends on awareness about the virus, various modes of transmission and its health effects in the community. New developments in the field of early detection and prophylaxis of cervical cancer offer new options to women and healthcare providers. An accurate knowledge about HPV, mode of transmission, preneoplastic lesions and invasive cancers help in making an informed choice. Most of the KAP studies about HPV are being conducted among adolescents and University students as the infection is highly prevalent among them and also they form the target population for HPV vaccination. We decided to conduct this study among rural women as there is a paucity of data especially among rural women and are often neglected in terms of healthcare facilities and health education.

${ }^{1}$ Department of Virus Research, ${ }^{2}$ Department of Obstetrics and Gynecology, Dr TMA Pai Hospital, ${ }^{3}$ Department of Community Medicine, Kasturba Medical College, Manipal University, Manipal, India*For correspondence: sabeenauthradam@gmail.com, sabeena.s@manipal.edu 


\section{Materials and Methods}

Study setting and study population

Perdoor village in Udupi Taluk, Udupi district, Karnataka State, India was the study area. Within Perdoor village, grampanchayath wards 2,3,5,6 and 7 with a total of 2000 women in the age group of 18-65 years were chosen for the study. Udupi Taluk in Udupi district is bound by Arabian Sea in the west and Western Ghats in the east and has a male literacy of $91.4 \%$ and female literacy rate of $81.6 \%$ (2011 Census).

\section{Study design}

A cross sectional, descriptive, house to house survey was conducted from June 2013-December 2014.

Sample size and sampling: A sample size of 971 was obtained on the assumption of expected prevalence of knowledge about HPV as $10 \%$ at $95 \%$ confidence interval and $20 \%$ bound on error. As there were no Indian studies, a community study from China was based to form the assumption (Li et al., 2009). Convenient sampling was used to recruit the subjects.

\section{Data collection tool}

A questionnaire was prepared to assess the sociodemographic characteristics, their knowledge, attitudes, and practice about HPV and its health effects. A series of Multiple choice Questions (MCQ)questions were prepared assessing the knowledge about various modes of transmission of HPV, its associations with cancer, outcomes of infection, and preventive options(five-point scale) as shown in Table 1.In the attitude section there are two positive and one negative statement with five options according to Likert's scale. Positive statements are "All sexually active women should undergo Pap smear test" and "HPV vaccine may increase multiple sexual partner behavior among adolescents". Negative statement is "HPV vaccine is not required for Indian women." Practices were assessed using four questions with Yes/No options. Data collection tool was prepared in consultation with experts from Clinical Psychology and Communication and validated by experts in the fields of Gynecology, Community Medicine and Microbiology. Questionnaire was pilot-tested for validity and reliability among 20 study participants.

\section{Data collection}

Households in ward 2,3,5,6,7 were visited with grass root health care workers if at least one lady in the age group of 18-65 years was residing in the house from august 2013 till December 2014. After obtaining informed consent and collection of sociodemographic data study participants were asked if they had heard of HPV. If a woman responded "no" -she was not asked further nine questions to assess the knowledge and three statements in the attitude section. However, questions on practices were asked to all the study participants.

\section{Data analysis}

Epidemiological data on social condition and reproductive aspects were obtained from all the participants by household surveys after taking informed written consent. Data included age, occupation, education, socioeconomic status, marital status, age at marriage, family history of malignancies, wood smoke exposure, alcohol consumption, and tobacco exposure. Data was entered into Epi Info 7. Descriptive statistics were reported using mean \pm SD for age and frequency and percentage for the categorical variables. To analyze the association of socioeconomic status, education and running water facility at home to various practices Chi-square analysis was performed considering a $\mathrm{P}$-value less than 0.05 as significant.

Study was approved by Institutional ethical committee of Kasturba Medical College, Manipal, and Manipal University (IEC 244/2013). Written informed consent in local language was taken before administering the data collection tool.

\section{Results}

A total of 1028 women were approached for conducting the study and 1020 women were enrolled into the study

Table 1. Socio-demographic Characteristics of HPV Study Participants $(\mathrm{n}=1020)$

\begin{tabular}{|c|c|c|}
\hline Socio-demographic factors & $\mathrm{N}$ & $(\%)$ \\
\hline \multicolumn{3}{|l|}{ Age groups(years) } \\
\hline $18-24$ & 145 & -14.2 \\
\hline $25-34$ & 281 & -27.6 \\
\hline $35-44$ & 236 & -23.1 \\
\hline $45-54$ & 210 & -20.6 \\
\hline $55-60$ & 93 & -9.1 \\
\hline $61-65$ & 55 & -5.4 \\
\hline \multicolumn{3}{|l|}{ Religion } \\
\hline Hindu & 972 & -95.3 \\
\hline Muslim & 46 & -4.5 \\
\hline Christian & 2 & -0.2 \\
\hline \multicolumn{3}{|l|}{ Socioeconomic status } \\
\hline Low & 618 & -60.6 \\
\hline Middle & 392 & -38.4 \\
\hline High & 10 & -1 \\
\hline \multicolumn{3}{|l|}{ Literacy } \\
\hline Illiterate & 146 & -14.3 \\
\hline Can read and write & 3 & -0.3 \\
\hline Can read only & 4 & -0.4 \\
\hline Primary & 171 & -16.8 \\
\hline Middle school & 261 & -26.6 \\
\hline High school & 255 & -25 \\
\hline PUC & 96 & -9.4 \\
\hline Graduate & 74 & -7.3 \\
\hline Post graduate & 10 & -0.9 \\
\hline \multicolumn{3}{|l|}{ Occupation } \\
\hline Home maker & 636 & -62.4 \\
\hline Cashew factory & 147 & -14.4 \\
\hline Beedi worker & 73 & -7.2 \\
\hline Coolie & 38 & -3.7 \\
\hline Tailor & 13 & -1.3 \\
\hline Teacher & 23 & -2.3 \\
\hline Students & 29 & -2.8 \\
\hline Business & 6 & -0.6 \\
\hline Asha worker & 4 & -0.4 \\
\hline Farmer & 14 & -1.4 \\
\hline Others & 32 & -3.1 \\
\hline
\end{tabular}


Knowledge, Attitude and Practice about HPV Infection and its Health Effects among Rural Women in Karnataka, South India

Table 2. Questions to Assess the Knowledge about HPV Infection and its Health Effects

\begin{tabular}{|c|c|c|c|c|c|}
\hline $\begin{array}{l}\text { What are the ways of acquiring } \\
\text { HPV infections? }\end{array}$ & Skin abrasions & Intercourse & Birth & All & Don't know \\
\hline $\begin{array}{l}\text { Some types of HPV infections } \\
\text { can cause cancers of }\end{array}$ & Ovary & Breast & Cervix & Stomach & Don't know \\
\hline $\begin{array}{l}\text { If a person is infected with } \\
\text { HPV,most cases will }\end{array}$ & Resolve & Progress & $\begin{array}{c}\text { Develop } \\
\text { preneoplastic } \\
\text { lesions }\end{array}$ & Cause cancer & Don't know \\
\hline $\begin{array}{l}\text { Chances of clearing HPV } \\
\text { infections decrease with }\end{array}$ & Increased age & $\begin{array}{c}\text { Multiple } \\
\text { sexual partners }\end{array}$ & $\begin{array}{l}\text { Early age at } \\
\text { marriage }\end{array}$ & Reduced immunity & $\begin{array}{l}\text { Don't know } \\
\text { All of the } \\
\text { above }\end{array}$ \\
\hline $\begin{array}{l}\text { HPV infection can be reduced by } \\
\text { all except }\end{array}$ & Immunization & Condoms & Health education & $\begin{array}{l}\text { Oral contraceptive } \\
\text { pills } \\
\end{array}$ & Don't know \\
\hline Pap smear screening will & $\begin{array}{l}\text { Not prevent } \\
\text { cervical cancer }\end{array}$ & $\begin{array}{c}\text { Will detect } \\
\text { cervical cancer } \\
\text { early }\end{array}$ & Not be helpful & $\begin{array}{l}\text { Increase the risk of } \\
\text { cervical cancer }\end{array}$ & Don't know \\
\hline $\begin{array}{l}\text { What is the treatment available } \\
\text { for HPV infection }\end{array}$ & Antibiotics & Steroids & Antivirals & None & Don't know \\
\hline $\begin{array}{l}\text { HPV infections can cause cancer } \\
\text { in }\end{array}$ & Men & Women & Both & None & Don't know \\
\hline $\begin{array}{c}\text { Commonest cancer among Indian } \\
\text { women }\end{array}$ & Breast cancer & Colon cancer & Lung cancer & Cervical cancer & Don't know \\
\hline Circle the wrong statement & $\begin{array}{l}\text { HPV vaccine } \\
\text { is available in } \\
\text { India }\end{array}$ & $\begin{array}{l}\text { HPV vaccine } \\
\text { can be given } \\
\text { to married } \\
\text { women }\end{array}$ & $\begin{array}{l}\text { HPV vaccine } \\
\text { should be given } \\
\text { before marriage } \\
\text { ideally }\end{array}$ & $\begin{array}{l}\text { HPV vaccine is } \\
\text { not expensive }\end{array}$ & \\
\hline
\end{tabular}

after written informed consent.

As shown in Table 2 majority of participants were in the age group of 25-44 (50.7\%). Mean age of study participants is 38.9 years $(\mathrm{SD}=12.6)$. Majority of the study participants were Hindus (95.3\%) while 46 women were Muslims (4.5\%) and two were Christians $(0.2 \%)$. According to Udai Pareek scale (Pareek and Trivedi, 1995), 618 (60.6\%) participants belonged to low socioeconomic status (Score $<40$ ). Most of the women had received education at least up to middle school (69.3\%) and 146(14.3\%) enrolled women were illiterates. According to occupation, there were $636(62.4 \%)$ homemakers, 147 (14.4\%) cashew factory workers, 73 (7.2\%) home based beedi rollers (thin Indian cigarette filled with tobacco flake), 23(2.3\%) teachers and other skilled/professional workers among the study population.

Most families live in mixed houses built of stones, cement and tiled roofs (79.8\%). Majority of the study population are non-vegetarians (92.9\%) and only about $7 \%$ are vegetarians. Firewood is the main fuel used for cooking by $80 \%$ families.

Running water facility inside house was reported by $488(47.8 \%)$ women and this is often indirectly related to genital hygiene. Homemade pads during menstruation were used by $766(75.1 \%)$ women and sanitary napkins by $223(22 \%)$ women. Use of both sanitary napkins and homemade clothes were reported by $31(2.9 \%)$ participants. Vaginal discharge was reported by $80(7.8 \%)$ women.

None of the participants gave history of smoking
Table 3. Distribution of practices related to HPV acquisition among study participants $(n=1020)$

\begin{tabular}{lrc}
\hline Answers & Number & $(\%)$ \\
\hline Does your partner use condoms? & & \\
$\quad$ Yes & 26 & -2.6 \\
$\quad$ No & 146 & -83.1 \\
$\quad$ No answer & -14.3 \\
Do you wash genital after intercourse? & 221 & -21.7 \\
$\quad$ Yes & 653 & -64 \\
$\quad$ No & 146 & -14.3 \\
$\quad$ No answer & & \\
Have you undergone pap screening? & 24 & 2.4 \\
$\quad$ Yes & 854 & 83.3 \\
$\quad$ No & 146 & 14.3 \\
$\quad$ No answer & & \\
Do you have more than one sexual partner & 1 & 0.09 \\
$\quad$ Yes & 873 & 85.6 \\
$\quad$ No & 146 & 14.3 \\
$\quad$ No answer & & \\
\hline
\end{tabular}

cigarettes /beedi. However Smokeless tobacco use in the form of pan or nasal powder was found among $145(14.2 \%)$ women. Alcohol intake was found among six women $(0.6 \%)$. Skin warts over face and hands of 13 women enrolled in the study were reported by interviewers. Partners of all Muslim women from study area had undergone circumcision $(n=42,4.4 \%)$. Mean age of menarche was 13.8years ( $\mathrm{S} . \mathrm{D}=1.5)$. Among the study participants, 256 (25\%) ladies had attained menopause and mean age of menopause is $45.7(\mathrm{SD}=5.4)$.

Among the enrolled women 146 (14.3\%) were 
Sabeena Sasidharan Pillai et al

unmarried and $874(85.7 \%)$ were sexually exposed. There were $777(76.2 \%)$ married women, $85(8.3 \%)$ widows, 11 $(1.1 \%)$ women separated from husbands and one divorcee among the study participants. Mean age of marriage was 22.2years $(\mathrm{SD}=4)$ and most women got married at 20 years of age or above (77.8\%). By 15 years of age, 21 women were married (2\%). Deliveries 5 or more $(5.5 \%)$ were reported by 48 women. Majority had vaginal delivery $(n=678,77.6 \%)$ and $100(11.4 \%)$ women had caesarean section. History of both the modes of delivery was reported by $30(3.4 \%)$ multiparous women. Most participants had hospital delivery $(n=559,69.1 \%)$ and $162(20.1 \%)$ women had home delivery. Home and hospital deliveries were reported by 87 women. At the time of enrollment 11 women were pregnant. History of abortion was given by $84(9.6 \%)$ women from study area and among them 41 had undergone dilatation and curettage. Most of the participants from the study area $(n=412,47.1 \%)$ are not practicing any methods of contraception. Tubal ligation was reported by 383 women $(43.8 \%)$. Condom use by partner was reported by 26 women $(2.6 \%)$ and 39 women reported use of intrauterine contraceptive device. Partners of eight women had undergone vasectomy. Six women had used of oral pills for 2-3 months and nobody reported use for more than 6 months.

Family history of malignancy was given by 62 women (6.1\%). Among the study group 17 participants reported head and neck cancers among family members (oral cancer, throat cancer, and jaw cancer). For various benign causes 18 women had undergone hysterectomy and they were also included in the study.

\section{Knowledge, Attitude and Practice about HPV and its health effects}

From the study area none of the study participants had heard of HPV and not at all aware of its health effects.

As shown in Table 3 after sexual contact 221women $(25.3 \%)$ reported washing of genital areas. There was positive association of genital hygiene with higher education (Chi-square value 159.3, p-value <0.001). Among 488 women who had running water facility at home, 148 reported washing of genitals (30.3\%) and among 532 women with no running water at home, only 70 women cleaned genitals after intercourse (13\%). This association was statistically significant (Chi-square-42.2, p-value $<0.001)$. Among the sexually exposed women only 24 women $(2.4 \%)$ were screened by Pap smear testing and $97.6 \%$ had not even heard of this screening test. Male condom use among partners was reported by 26 women (2.6\%). Only one lady, a widow reported sexual contact with multiple partners.

Because of cultural issues questions like "Does your partner use condoms?" "Do you wash genitals after intercourse?" were not asked to unmarried women and their response was marked as no answer as shown in Table 3.

\section{Discussion}

In our study none of the participants had heard of HPV and unaware of its health effects even though it is one of the commonest sexually transmitted infections.

According to studies published in last fourteen years, $15-31 \%$ of women of all ages have heard of HPV infection and this ranges from $13-93 \%$ in studies conducted among young women worldwide (Klug et al., 2008). Most of these studies had been conducted in United States among medical students, University students and urban adolescents. As such there are fewer studies among rural women worldwide. From rural area of Southern USA, one fourth of the study population had heard of HPV (Cates et al., 2009). A telephonic survey from Quebec, Canada, conducted among adults found low awareness about HPV infection and only $15 \%$ had heard of HPV (Sauvageau et al., 2007). According to another telephonic survey carried out among women aged 18 to 61 years, randomly selected from households in Victoria, Australia, more than half of the study participants had heard of HPV (Pitts et al., 2007). Two international web based surveys conducted in US, UK and Australia found most participants had heard of HPV (Dodd et al., 2014). Even though there was no significant difference between countries, women scored better than men in all the places. These surveys carried out among urban women also emphasize the fact that despite $50-60 \%$ had heard of HPV, overall knowledge is low. Sub-Saharan Africa has a very high HPV prevalence among sexually active women and is estimated to be 24 $\%$ (Anorlu, 2008). A household survey conducted in a peri-urban village in Mali, West Africa among adults, adolescent men, and women found only $2 \%$ knew that HPV is a sexually transmitted infection. Community study done among women from Abu Dhabi found only $38 \%$ was aware of HPV, inspite of launching a cervical cancer screening programme in 2013 (Ortashi et al., 2013). Whereas, higher awareness was found among women regarding HPV in community study from Turkey (Dursun et al., 2009). Population studies from Hong Kong, China and Malaysia reveals low level of knowledge about HPV and vaccination. (Lee et al., 2007; Li et al., 2009; Wong, 2011). According to a recently published study among suburban and rural communities from Nepal, 15.4\% women in the reproductive age group had heard of HPV (Johnson et al., 2014).

There are lot of KAP studies conducted among health professionals, University students, college students and Medical students from all over the world. They show higher rate of awareness about the HPV virus and vaccine compared to rural women (Aldrich et al., 2005; Reiter et al., 2011; Vogtmann et al., 2011; Ortashi et al., 2012; Rashwan et al., 2012; Sanaullah et al., 2012; Genc et al., 2013). There are few hospital and outpatient clinic based studies from different parts of the world (Donders et al., 2008; Rama et al., 2010; Paolino and Arrossi, 2011; Belani et al., 2014).

From India few knowledge, attitudes and practice studies about HPV are there among University students ,medical students, urban adolescent sand patients (Saha et al., 2010; Pandey et al., 2012; Mehta et al., 2013; Ramavath and Olyai, 2013; Belani et al., 2014). Another study from Mangalore city, Karnataka shows better awareness among women attending post natal and family practice clinics and $36 \%$ had heard of HPV infection through media or 
Knowledge, Attitude and Practice about HPV Infection and its Health Effects among Rural Women in Karnataka, South India

informed by a doctor(Montgomery MP, 2014).

Total ignorance about HPV and its health effects among rural women in our study may be due to the absence of organized cervical screening programmes in India. Higher level of knowledge among women was found in developing countries where there are population based cervical cancer screening and health education programmes. In our study HPV awareness was not at all correlated with the level of education unlike studies from UK, USA and Australia (Marlow et al., 2013). Majority of the study participants were from low socioeconomic status and were home makers. Most of them belonged to Hindu community and were non-vegetarians. As per latest information in South India $10-20 \%$ of the rural population are vegetarians (Shridhar et al., 2014). In our study only $7 \%$ study participants are following vegetarian diet. According to a community study from North India non-vegetarian diet and rural settings are significant independent predictors for HPV infection (Srivastava et al., 2012). Because of social customs getting a history of sexual exposure from unmarried women is difficult and we assumed that all unmarried women are sexually naïve. In our study more than three fourth of the study population were married at 20 years and above. Younger age at sexual exposure is considered an important risk factor for HPV infection as the immature cervical transformation zone in adolescents is particularly susceptible to infection (Kanato and Saranrittichai, 2006). Smoking and alcohol intake are indirectly related to unsafe sexual practices and HPV infection (Veldhuijzen et al., 2010). From the study area use of smokeless tobacco in the form of pan and nasal powder was found among few women and very few women were found to be taking alcoholic beverages.

Use of condoms by partners can protect the women to some extent from initial HPV infection (Moscicki et al., 2012). In our study male condom usage was low in the area. Male circumcision is widely practiced among Muslim men and husbands of all Muslim ladies in the study had undergone circumcision. On the basis of metaanalysis of studies conducted in last forty years male circumcision can reduce genital HPV infection and High risk HPV prevalence among men (Albero et al., 2012). In the practice section only one fourth of study population reported washing of genitals after sexual exposure. Pap smear screening coverage was very low among the enrolled women. None of the women complained of vaginal discharge had undergone Pap smear test.

Limitations: Main limitation of our study was non probability convenience sampling method. Findings of this study cannot be generalized to all Indian rural women as Perdoor village with a female literacy rate of $86 \%$ and mean age at marriage 22years may not be the true representation of rural India and there is vast cultural and social diversity across all over India.

Strength of our study: To best of our knowledge this is the first community based study about knowledge, attitude and practice about Human Papilloma Virus infection and its health effects from rural India. A large number of rural women, more than 1000 were surveyed from 5 wards of a village by house visit. Pretested data sheet was used and each participant was personally interviewed by the investigator or trained health care workers. An attempt was made to include all sociodemographic factors shown in previous community based studies conducted in India (Sankaranarayanan et al., 2009; Srivastava et al., 2012) . We could establish a cohort of 1020 asymptomatic rural women in the age group of 18-65 years and initiate health education activities.

In conclusion, according to this community based study, rural women from Karnataka, India are totally unaware of HPV infection and its health effects. Proper information about HPV, cervical cancer and preventive options will improve the participation of rural women in screening programmes. Awareness about the virus and its health effects will enable the women in modifying their health compromising behaviors.

A proactive approach by health care workers in educating the rural women about healthy life style, genital hygiene and at least once in a life time screening after 40 years can definitely reduce the incidence and mortality from cervical cancer in developing countries.

\section{Acknowledgements}

Financial support from ICMR project File no.5/8/7/15/2010/ECD-I. Dr Sabeena.S is a research scientist-II in this project.

We also acknowledge the valuable help provided by Junior Health Assistant Mrs.Vimala Bairy and grass root health workers, Mrs. YashodaNaik, Mrs.Radha Bhat, Mrs Saraswathi Shetty, and Mrs Jayanthi.

\section{References}

Albero G, Castellsague X, Giuliano AR, et al (2012). Male circumcision and genital human papillomavirus: a systematic review and meta-analysis. Sex Transm Dis, 39, 104-13.

Aldrich T, Becker D, Garcia SG, et al (2005). Mexican physicians' knowledge and attitudes about the human papillomavirus and cervical cancer: a national survey. Sex Transm Infect, 81, 135-41.

Anorlu RI (2008). Cervical cancer: the sub-Saharan African perspective. Reprod Health Matters, 16, 41-9.

Belani HK, Sekar P, Guhaniyogi R, et al (2014). Human papillomavirus vaccine acceptance among young men in Bangalore, India. Int J Dermatol, 53, 486-91.

Bhatla N, Lal N, Bao YP, et al (2008). A meta-analysis of human papillomavirus type-distribution in women from South Asia: implications for vaccination. Vaccine, 26, 2811-7.

Cates JR, Brewer NT, Fazekas KI, et al (2009). Racial differences in HPV knowledge, HPV vaccine acceptability, and related beliefs among rural, southern women. J Rural Health, 25, 93-7.

Dodd RH, McCaffery KJ, Marlow LA, et al (2014). Knowledge of human papillomavirus (HPV) testing in the USA, the UK and Australia: an international survey. Sex Transm Infect, 90, 201-7.

Donders GG, Gabrovska M, Bellen G, et al (2008). Knowledge of cervix cancer, human papilloma virus (HPV) and HPV vaccination at the moment of introduction of the vaccine in women in Belgium. Arch Gynecol Obstet, 277, 291-8.

Dursun P, Altuntas B, Kuscu E, et al (2009). Women's knowledge about human papillomavirus and their acceptance of HPV vaccine. Aust N Z J Obstet Gynaecol, 49, 202-6.

Genc RE, Sarican ES, Turgay AS, et al (2013). Determination 
Sabeena Sasidharan Pillai et al

of knowledge of Turkish midwifery students about human papilloma virus infection and its vaccines. Asian Pac J Cancer Prev, 14, 6775-8.

IARC. 2013 Latest world cancer statistics Global cancer burden rises to 14.1 million new cases in 2012 [Online].

ICO. 2014. ICO Information Centre on HPV and Cancer (HPV Information 2014.

Johnson DC, Bhatta MP, Gurung S, et al (2014). Knowledge and awareness of human papillomavirus (HPV), cervical cancer and HPV vaccine among women in two distinct Nepali communities. Asian Pac J Cancer Prev, 15, 8287-93.

Kanato M, Saranrittichai K (2006). Early experience of sexual intercourse--a risk factor for cervical cancer requiring specific intervention for teenagers. Asian Pac J Cancer Prev, 7, 151-3.

Klug SJ, Hukelmann M, Blettner M (2008). Knowledge about infection with human papillomavirus: a systematic review. Prev Med, 46, 87-98.

Lee PW, Kwan TT, Tam KF, et al (2007). Beliefs about cervical cancer and human papillomavirus (HPV) and acceptability of HPV vaccination among Chinese women in Hong Kong. Prev Med, 45, 130-4.

Li J, Li LK, Ma JF, et al (2009). Knowledge and attitudes about human papillomavirus (HPV) and HPV vaccines among women living in metropolitan and rural regions of China. Vaccine, 27, 1210-5.

Marlow LA, Zimet GD, McCaffery KJ, et al (2013). Knowledge of human papillomavirus (HPV) and HPV vaccination: an international comparison. Vaccine, 31, 763-9.

Mehta S, Rajaram S, Goel G, et al (2013). Awareness about Human Papilloma Virus and its Vaccine Among Medical Students. Indian J Community Med, 38, 92-4.

Montgomery MP DT (2014). Knowledge and acceptability of human papillomavirus vaccination and cervical cancer screening among women in karnataka India. J Cancer Educ.

Moscicki AB, Schiffman M, Burchell A, et al (2012). Updating the natural history of human papillomavirus and anogenital cancers. Vaccine, 30, 24-33.

Ortashi O, Raheel H, Shalal M, et al (2013). Awareness and knowledge about human papillomavirus infection and vaccination among women in UAE. Asian Pac J Cancer Prev, 14, 6077-80.

Ortashi O, Shallal M, Osman N, et al (2012). Knowledge, attitude and practice of school nurses in the United Arab Emirates about HPV infection and vaccine. Asian Pac J Cancer Prev, 13, 6481-4.

Pandey D, Vanya V, Bhagat S, et al (2012). Awareness and attitude towards human papillomavirus (HPV) vaccine among medical students in a premier medical school in India. PLoS One, 7, 40619.

Paolino M, Arrossi S (2011). Women's knowledge about cervical cancer, Pap smear and human papillomavirus and its relation to screening in Argentina. Women Health, 51, 72-87.

Pareek U, Trivedi P 1995. Manual of Socioeconomic Status Scale(rural), New Delhi.

Pitts MK, Dyson SJ, Rosenthal DA, et al (2007). Knowledge and awareness of human papillomavirus (HPV): attitudes towards HPV vaccination among a representative sample of women in Victoria, Australia. Sex Health, 4, 177-80.

Rama CH, Villa LL, Pagliusi S, et al (2010). Awareness and knowledge of HPV, cervical cancer, and vaccines in young women after first delivery in Sao Paulo, Brazil--a crosssectional study. BMC Womens Health, 10, 35.

Ramavath KK, Olyai R (2013). Knowledge and awareness of hpv infection and vaccination among urban adolescents in india: a cross-sectional study. J Obstet Gynaecol India, 63, 399-404.
Rashwan HH, Saat NZ, Abd Manan DN (2012). Knowledge, attitude and practice of malaysian medical and pharmacy students towards human papillomavirus vaccination. Asian Pac J Cancer Prev, 13, 2279-83.

Reiter PL, Stubbs B, Panozzo CA, et al (2011). HPV and HPV vaccine education intervention: effects on parents, healthcare staff, and school staff. Cancer Epidemiol Biomarkers Prev, 20, 2354-61.

Saha A, Chaudhury AN, Bhowmik P, et al (2010). Awareness of cervical cancer among female students of premier colleges in Kolkata, India. Asian Pac J Cancer Prev, 11, 1085-90.

Sanaullah M, Bashir S, Bhatti JA, et al (2012). Promotion of HPV vaccination: potential gaps between knowledge and practices of Pakistani female family practitioners. J Fam Plann Reprod Health Care, 38, 208-9.

Sankaranarayanan R, Nene BM, Shastri SS, et al (2009). HPV screening for cervical cancer in rural India. $N$ Engl J Med, 360, 1385-94.

Sauvageau C, Duval B, Gilca V, et al (2007). Human papilloma virus vaccine and cervical cancer screening acceptability among adults in Quebec, Canada. BMC Public Health, 7, 304.

Shridhar K, Dhillon PK, Bowen L, et al (2014). Nutritional profile of Indian vegetarian diets--the Indian Migration Study (IMS). Nutr J, 13, 55.

Shukla S, Bharti AC, Mahata S, et al (2009). Infection of human papillomaviruses in cancers of different human organ sites. Indian J Med Res, 130, 222-33.

Srivastava S, Gupta S, Roy JK (2012). High prevalence of oncogenic HPV-16 in cervical smears of asymptomatic women of eastern Uttar Pradesh, India: a population-based study. J Biosci, 37, 63-72.

Veldhuijzen NJ, Snijders PJ, Reiss P, et al (2010). Factors affecting transmission of mucosal human papillomavirus. Lancet Infect Dis, 10, 862-74.

Vogtmann E, Harlow SD, Valdez AC, et al (2011). HPV knowledge in Mexican college students: implications for intervention programmes. Health Soc Care Community, 19, 148-57.

Wong LP (2011). Knowledge of and attitudes toward the HPV vaccine among multi-ethnic women from urban/university and rural areas. Int J Gynaecol Obstet, 112, 146-7. 